\title{
Survival of Phytophthora infestans Sporangia Exposed to Solar Radiation
}

\author{
Eduardo S. G. Mizubuti, Donald E. Aylor, and William E. Fry
}

First and third authors: Department of Plant Pathology, Cornell University, Ithaca, NY 14853; second author: Department of Plant Pathology and Ecology, The Connecticut Agricultural Experiment Station, P. O. Box 1106, New Haven 06504.

Current address of E. S. G. Mizubuti: Departamento de Fitopatologia, Universidade Federal de Viçosa, 36571-000 Viçosa, MG, Brazil. Accepted for publication 16 September 1999.

\begin{abstract}
Mizubuti, E. S. G., Aylor, D. E., and Fry, W. E. 2000. Survival of Phytophthora infestans sporangia exposed to solar radiation. Phytopathology 90 : 78-84.

The effect of solar irradiance (SI) on the viability of sporangia of isolates belonging to two clonal lineages, US-1 and US-8, of Phytophthora infestans was assessed. Exposure during a 3-h period on sunny days (SI >

of the exposure. After $1 \mathrm{~h}$ of exposure on sunny days, the viability of sporangia decreased by $\approx 95 \%$, and the effective time necessary to inactivate $95 \%$ of the sporangia was $1.1 \mathrm{~h}$. The effective dose to inactivate $95 \%$ of the sporangia on sunny days was $2.6 \mathrm{MJ} / \mathrm{m}^{2}$. On overcast (SI < $300 \mathrm{~W} / \mathrm{m}^{2}$ ) days, survival after $3 \mathrm{~h}$ was reduced only slightly. Thus, other variables being equal, sporangia will survive hours longer in the atmosphere on cloudy days than on sunny days.
\end{abstract} $600 \mathrm{~W} / \mathrm{m}^{2}$ ) drastically reduced germination regardless of the time of day
Aerial dispersal of inoculum is important in the epidemiology of many plant diseases $(1,3,7,9,14,22)$. Aerial dispersal of Phytophthora infestans (Mont.) De Bary sporangia is the main process involved in spreading potato (Solanum tuberosum L.) and tomato (Lycopersicon esculentum Mill.) late blight epidemics $(8,17,18)$. Survival of sporangia during dispersal is crucial for spatial increase of disease.

One of our long-range goals is to develop an area-wide forecast system for late blight, and the amount of viable inoculum coming into a production field is an important factor. Knowledge of sporangium survival during dispersal could be a key component to development of area-wide forecast systems, because sporulating lesions in one field can provide inoculum to initiate infections in neighboring fields. Solar irradiance (SI), temperature, and relative humidity $(\mathrm{RH})$ are the most important weather variables that influence the survival of $P$. infestans sporangia $(6,15,23)$. The effects of RH and temperature have been described (23), but the effects of SI on viability of sporangia have not yet been quantified. Most of the deleterious effects of sunlight on biological systems are due to radiation in the UV spectrum; UV-B (280 to $310 \mathrm{~nm})$ is the most active form of radiation (11).

The effects of SI on viability of fungal and oomycete spores vary among and within taxa $(2,12,16,19,21,26,29)$. For example, although spores of Alternaria solani can tolerate high doses of SI (29), basidiospores of Exobasidium vexans, causal agent of tea blister blight, cannot. The viability of $E$. vexans basidiospores was reduced after exposure to solar radiation for $1.5 \mathrm{~h}$ on sunny days (32). Oomycete sporangia and conidia are expected to be sensitive to the aerial environment. In one study, the viability of detached Peronospora tabacina sporangia exposed to $3 \mathrm{~h}$ of direct solar radiation was reduced to $\approx 3 \%$ that of nonexposed spores (29). In another study, the viability of Peronospora destructor sporangia was low after $4 \mathrm{~h}$ of exposure to direct solar radiation (5).

$P$. infestans sporangia are likely to be sensitive to SI. According to De Weille (10), visible and infrared irradiance from controlled sources had no influence on the viability of detached sporangia,

Corresponding author: W. E. Fry; E-mail address: wef1@ cornell.edu

Publication no. P-1999-1026-01R

(C) 2000 The American Phytopathological Society whereas moderate doses of UV reduced viability. The effect of total solar radiation on sporangium survival under field conditions is likely to interact with other weather factors, such as temperature and $\mathrm{RH}$, and results obtained under laboratory conditions may not accurately represent field situations. Some reports suggest that sunlight reduces the viability of detached sporangia of $P$. infestans (28), and Glendinning et al. (12) reported that exposure for $1 \mathrm{~h}$ to direct solar radiation on a sunny day was enough to inactivate sporangia of $P$. infestans, but no quantitative data were provided. For disease forecasting, it is necessary to quantify the effect of total solar radiation on the viability of $P$. infestans sporangia.

The objective of our study was to quantify the effect of total solar radiation (direct plus diffuse) on the viability of sporangia of $P$. infestans. Because there are new clonal lineages or genotypes of $P$. infestans (13) that respond differently to certain environmental factors, such as temperature (24), we also tested the hypothesis that sporangia of isolates belonging to two clonal lineages of the pathogen are differentially sensitive to SI. We used US-1, the "old" lineage that is thought to have been in the United States and worldwide for more than a century, and US-8, the "new" lineage recently introduced into the United States. The experimental approach was to expose sporangia of different isolates to solar radiation on sunny or cloudy days and quantify the effects of SI on sporangium germinability.

\section{MATERIALS AND METHODS}

Three sets of experiments were conducted near the Cornell University campus at Freeville, NY (42 $30^{\prime} 50^{\prime \prime} \mathrm{N}$ and $76^{\circ} 20^{\prime} 49^{\prime \prime} \mathrm{W}$, elevation $319 \mathrm{~m}$ ). In the first set, sporangia were exposed for $3 \mathrm{~h}$ at different times of the day on sunny days. The second set was composed of a series of experiments conducted either on sunny or cloudy days, with sporangia exposed for up to $3 \mathrm{~h}$ during each of the days. The third set of experiments was conducted on sunny days, with sporangia exposed for up to $1 \mathrm{~h}$ each day (Table 1). All experiments were conducted from July to September during 1995, 1996, and 1997.

Sporangia production. Sporangia were obtained from sporulating lesions on potato leaves. For the first set of experiments, three isolates each of the US-1 and US-8 clonal lineages of $P$. infestans were used. Inoculated cv. Norchip plants in the greenhouse 
were covered with plastic bags moistened with water droplets to form a moist chamber during the first $24 \mathrm{~h}$ after inoculation. After this time, the plastic bags were removed, and the plants were transported to an area adjacent to the field to allow sporulation to occur under natural environment conditions.

For the second and third sets of experiments, US-8 sporangia were collected from infected field-grown plants in our experimental plots; US-1 sporangia were from greenhouse-grown plants. There was no source of plants in the field infected with US-1 isolates, and we did not inoculate plants in the field with US-1 (A1 mating type), because we did not want to create a potential for sexual reproduction with US-8 (A2 mating type, the most common lineage in the northeastern United States and the lineage with which our field plots were inoculated). Infected leaflets from field-grown plants were picked during the morning between 0830 and $0900 \mathrm{~h}$ and transported in a container to the laboratory, where sporangia were collected.

In all cases, leaflets with lesions were allowed to dry for $30 \mathrm{~min}$ at room temperature in a shelter near the field, because sporangia from moist lesions are more sensitive to drying than those from dry lesions (23). Sporangia were transferred to membrane filters (47-mmdiameter, $0.45-\mu \mathrm{m}$-pore, mixed cellulose esters membrane filters) (Supor-450, Gelman Science, Ann Arbor, MI) by gently touching a lesion with a filter.

Exposure methodology. Sporangia were exposed to different conditions while on the filters. The filters rested on a grid $(2.0 \times 2.0 \mathrm{~cm})$ of nylon threads connected to a completely white wooden frame, $85 \mathrm{~cm}$ long $\times 40 \mathrm{~cm}$ wide. This support system allowed good ventilation and, consequently, a reasonable temperature equilibrium between membrane filters and ambient air. A roof made of plywood ( $3 \mathrm{~mm}$ thick) was attached to the wooden frame along the longitudinal axis, such that half of the grid was covered to provide an area shaded from direct solar radiation, and the other half was uncovered. The surface of the roof exposed to the sun was covered with aluminum foil. No lining was used for the inside surface. The roof was positioned $18 \mathrm{~cm}$ above the membrane filters to allow good ventilation (Fig. 1).

Membrane filters containing sporangia were attached to the nylon threads with regular tape, with the sticky side facing up. The wooden support was maintained at $1.2 \mathrm{~m}$ above ground level in a horizontal position. The frame was placed such that its length was oriented east to west, along the sun path.

Sporangia on membrane filters were subjected to one of three treatments: direct exposure to sunlight $(\mathrm{S})$; protected from direct radiation (covered under the roof, $\mathrm{C}$ ); and not exposed at all $(\mathrm{N})$, maintained on top of a lab bench for the duration of the experiment. The amount of diffuse radiation inside was approximately one-tenth of the amount measured outside.

Germination assessment. After exposure, sporangia on membrane filters were transferred to a moist chamber to allow slow rehydration (necessary to maintain viability of sporangia [23]). A moist chamber was created with a $15-\mathrm{cm}$ petri plate, the lid of which was lined with wetted filter paper. Membranes were kept in the petri plate below the wetted filter paper but not in direct contact with it. After $15 \mathrm{~min}$ in the moist chamber, sporangia on filters

TABLE 1. Summarized description of experiments designed to investigate the effects of solar radiation on survival of Phytophthora infestans sporangia

\begin{tabular}{lcccc}
\hline Exp. $^{\text {a }}$ & $\begin{array}{c}\text { Time of } \\
\text { exposure (h) }\end{array}$ & $\begin{array}{c}\text { Length of } \\
\text { exposure (h) }\end{array}$ & $\begin{array}{c}\text { Sampling } \\
\text { interval (min) }\end{array}$ & $\begin{array}{c}\text { Sky } \\
\text { condition }\end{array}$ \\
\hline 1 & 0800 to 1100 & 3 & 60 & Sunny \\
& 1100 to 1400 & 3 & 60 & Sunny \\
$2 \mathrm{~S}$ & 1400 to 1700 & 3 & 60 & Sunny \\
$2 \mathrm{C}$ & 1100 to 1400 & 3 & 60 & Sunny \\
& 1100 to 1400 & 3 & 60 & Cloudy \\
3 & 1100 to 1200 & 1 & 15 & Sunny \\
\hline
\end{tabular}

a $\mathrm{S}=$ direct exposure to sunlight; $\mathrm{C}=$ indirect exposure, covered by a roof. were transferred to water agar $(1.5 \%)$ in petri dishes and incubated at $15^{\circ} \mathrm{C}$. Germination assessments were made after $24 \mathrm{~h}$ of incubation by counting at least 300 sporangia per replicate with the aid of a microscope (100x) and recording the number that were germinated and ungerminated. No distinction was made between indirect or direct sporangial germination, but the majority of sporangia germinated indirectly to form zoospores.

In preliminary experiments, we observed that the source of sporangia affected their sensitivity to environmental conditions. Sporangia produced on culture medium or detached leaflets kept in small moist chambers were more sensitive to SI dose and desiccation than were sporangia produced on lesions in the field. Therefore, to avoid large qualitative differences in sporangia sensitivity, only sporangia produced in planta and under field conditions (when possible) were used in the experiments.

Experiment 1: Sporangia exposure for 3-h periods during sunny days. Sporangia of three isolates (Table 2) of US-1 and three isolates of US-8 were exposed to solar radiation on sunny days. A sunny day (SI $>600 \mathrm{~W} / \mathrm{m}^{2}$ ) with relatively calm winds was divided into three time periods: from 0800 to 1100,1100 to 1400 , and 1400 to $1700 \mathrm{~h}$. Sporangia were exposed during all three periods. The isolates of both clonal lineages were exposed on the same days.

Each isolate (US-1 or US-8) and treatment (S, C, or N) combination for each exposure period had two replications (two membrane filters with sporangia). Membranes were distributed randomly on the shaded and exposed areas of the support. The experimental design was completely randomized. The experiment was repeated on two days.

Experiment 2: Sporangia exposure for 3-h periods during sunny and cloudy days. Because the results of experiment 1 indicated that viability was drastically reduced after a 3-h exposure period on sunny days (discussed below), the dynamics of sporangium survival during the $3-\mathrm{h}$ period on sunny $\left(\mathrm{SI}>600 \mathrm{~W} / \mathrm{m}^{2}\right.$ ) and cloudy $\left(\mathrm{SI}<400 \mathrm{~W} / \mathrm{m}^{2}\right.$ ) days was investigated. Sporangia of

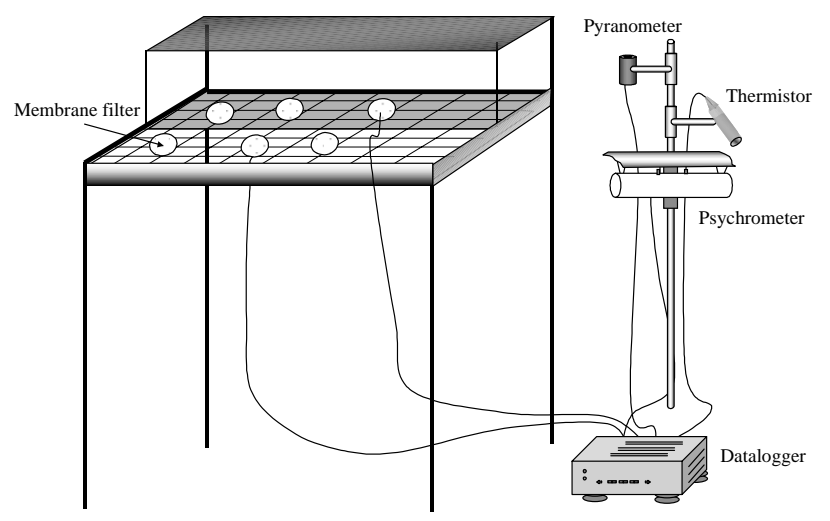

Fig. 1. Schematic representation of the apparatus used as a support for exposing membrane filters bearing sporangia of Phytophthora infestans to solar radiation.

TABLE 2. Isolates of the US-1 and US-8 clonal lineages (CL) of Phytophthora infestans used in experiments

\begin{tabular}{lcccc}
\hline Isolate $^{\mathrm{a}}$ & CL & Exp. 1 & Exp. 2 & Exp. 3 \\
\hline US940499 & US-1 & $+^{\mathrm{b}}$ & & \\
US940500 & US-1 & + & & \\
US940501 & US-1 & + & + & + \\
US940467 & US-8 & & + & + \\
US940473 & US-8 & + & & \\
US940474 & US-8 & + & & \\
US940495 & US-8 & + & & \\
\hline
\end{tabular}

a Isolate reference number from the Cornell University Phytophthora infestans culture collection.

${ }^{\mathrm{b}}$ Isolate was used in the experiment.. 

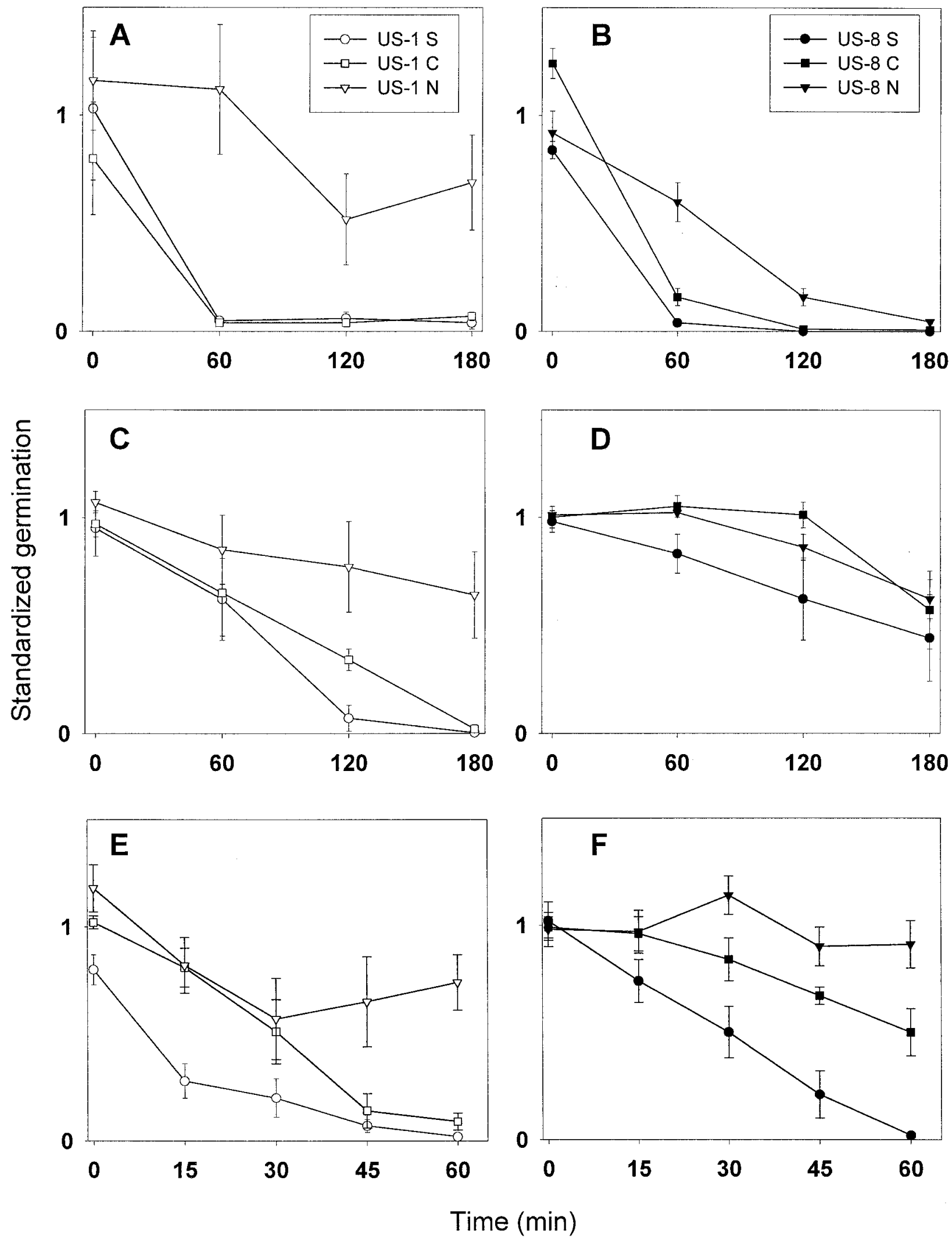

Fig. 2. Average standardized germination percentage of sporangia of isolates belonging to two clonal lineages of Phytophthora infestans, A, C, and E, US-1 and B, D, and F, US-8, as a function of duration of exposure. Sporangia were directly exposed to solar radiation (S), covered under shade conditions (C), or not exposed to solar radiation (N) in three different experiments: A and B, US-1 and US-8 isolates, respectively, exposed on sunny days for $3 \mathrm{~h}$ from 1100 to $1400 \mathrm{~h}$; $\mathbf{C}$ and D, US-1 and US-8 isolates, respectively, exposed on cloudy days for $3 \mathrm{~h}$ from 1100 to $1400 \mathrm{~h} ; \mathbf{E}$ and F, US-1 and US-8 isolates, respectively, exposed on sunny days for $1 \mathrm{~h}$ from 1100 to $1200 \mathrm{~h}$. Standardized germination was calculated by dividing the absolute germination percentages of sporangia exposed to solar irradiance $\left(G_{\mathrm{S}}\right.$ or $G_{\mathrm{C}}$, respectively; treatment $\mathrm{S}$ or $\mathrm{C}$ ) by the average of the absolute germination percentage of nonexposed (N) sporangia at the beginning of the exposure (time $0 ; G_{0}$ ). Mean of two experiments. Bars represent standard error of the mean. 
one isolate each of US-1 and US-8 (Table 2) were exposed during sunny and cloudy days, and viability was assessed at hourly intervals. Exposure periods were from 1100 to $1400 \mathrm{~h}$. This interval was chosen because it typically corresponds to a high sporangia concentration in the air (17) and maximum daily SI. Membrane filters containing sporangia were removed from the mounting frame at $0,60,120$, and $180 \mathrm{~min}$ of exposure. Three membrane filters were sampled from each isolate (US-1 or US-8) and treatment ( $\mathrm{S}, \mathrm{C}$, or $\mathrm{N}$ ) combination at every hour. The experiment was set in a completely randomized design, with three replicates per sample time. Each replicate consisted of a membrane filter containing sporangia that was randomly positioned on the shaded and exposed areas of the support. For each isolate, the experiment was conducted on two sunny and two cloudy days. Isolates of the clonal lineages were exposed on different days.

Experiment 3: Sporangia exposure for $1 \mathrm{~h}$ during sunny days. A third set of experiments was performed to determine the effect of SI on sporangium viability within a 1-h exposure period, from 1100 to $1200 \mathrm{~h}$, on sunny days. Sporangia of one isolate each of US-1 and US-8 (Table 2) were collected and exposed. Samples were taken at 0-, 15-, 30-, 45-, and 60-min intervals. Three membrane filters were sampled from each isolate (US-1 or US-8) and treatment $(\mathrm{S}, \mathrm{C}$, or $\mathrm{N})$ combination at each sample time and transferred to a moist chamber. Incubation conditions and viability assessments were performed as described for experiment 2 . The experiment was set in a completely randomized design, with three replicates per sample time. Each replicate consisted of a membrane filter that was randomly positioned on the shaded and exposed areas of the support. The experiment for each isolate was conducted twice (on different days). Each isolate was exposed on each of two sunny days. Isolates were exposed on different days, i.e., US-8 and US-1 isolate were not exposed concurrently on a given day.

Meteorological measurements. For all experiments, fine $(0.13 \mathrm{~mm})$ wire type-T thermocouples (Omega Instruments, Stamford, CT) were attached to the bottom of two membrane filters attached to the mounting frame. No sporangia were transferred to these membranes. One membrane was directly exposed to the sun (S), and the other was kept under shade (C). A force-ventilated psychrometer was constructed and used to determine RH, and thermistors were used to monitor air temperature. Total solar radiation (direct plus diffuse) was measured with a pyranometer (200SZ, Li-Cor Inc., Lincoln, NE) set in a horizontal position and located at the same height (1.2 $\mathrm{m}$ above the ground) as the membrane filters attached to the frame. SI dose (megajoules per square meter), average SI (watts per square meter) multiplied by time (seconds) of exposure, were calculated All instruments were installed $1 \mathrm{~m}$ from the center of the wooden frame, and data were collected with a datalogger (CR10, Campbell Scientific, Logan, UT) programmed to sample the sensors at 1-s intervals and to output averages every $5 \mathrm{~min}$. The temperature of the room in which sporangia were kept in the nonexposed treatment $(\mathrm{N})$ was monitored every 15 min with a mercury thermometer or hygrothermograph.

Data analysis. Treatments were compared using standardized germination calculated as follows. First, the average of absolute germination percent for nonexposed $(\mathrm{N})$ sporangia at the beginning of the exposure (time 0$)\left(G_{0}\right)$ was calculated. Second, the absolute germination percentages of sporangia subjected to the treatments exposed to SI (S or C) were calculated ( $G_{\mathrm{S}}$ or $G_{\mathrm{C}}$, respectively); the percents were standardized by dividing by $G_{0}\left(G_{\mathrm{S}} / G_{0}\right.$ or $G_{\mathrm{C}} / G_{0}$, respectively).

Analyses were performed on at least two iterations of each experiment. For each clonal lineage there were (i) two 3-h experiments conducted on sunny days; (ii) two 3 -h experiments conducted on cloudy days; and (iii) two 1-h experiments conducted on sunny days. Data from the two experiments for each clonal lineage in each situation (i, ii, or iii) were pooled for statistical analyses after testing for equal variances using a Hartley's $F$-maximum test (20).

An exponential decay model, $Y=A_{1} \exp \left(-b_{1} X\right)(2,30)$, in which $A_{1}$ and $b_{1}$ are parameters estimated by nonlinear regression and $X=$
SI dose (megajoules per square meter) or time (minutes), respectively, was fit for each isolate in each of the experiments. The nonlinear model was fit using Proc NLIN (SAS statistical software, version 6.12, SAS Institute, Cary, NC). Correlation analyses were performed using Bonferroni-adjusted significance level for overall $\alpha=0.05$. The standardized germination percents were log-transformed for correlation analyses. SYSTAT software (SPSS, Chicago) was used for correlation analyses.

\section{RESULTS}

Experiment 1. After a 3-h exposure period on sunny days, the viability of all sporangia in treatments $\mathrm{S}$ and $\mathrm{C}$ was practically zero, regardless of the time of the day of exposure. The average absolute germination percentages of sporangia not exposed to solar radiation $\left(G_{\mathrm{N}}\right)$ were 40.40 and $11.40 \%$ for the US- 1 and US-8 isolates, respectively. The absolute germination percentages of US-1 and US- 8 sporangia in treatment $\mathrm{S}$ (directly exposed to the sun) after $3 \mathrm{~h}$ were 0.23 and $0.00 \%$, respectively, for exposures from 0800 to $1100 \mathrm{~h} ; 0.13$ and $0.00 \%$, respectively, for exposures from 1100 to $1400 \mathrm{~h}$; and $0.00 \%$ for both lineages for exposures from 1400 to $1700 \mathrm{~h}$. For sporangia in treatment $\mathrm{C}$ (protected from direct beam radiation), the absolute percentages of germination of US-1 and US-8 isolates were, respectively, 0.00 and $0.03 \%$ from 0800 to $1100 \mathrm{~h}$; 0.00 and $0.00 \%$ from 1100 to $1400 \mathrm{~h}$, and 0.03 and $0.00 \%$ from 1400 to $1700 \mathrm{~h}$. SI dose was similar for both days, and the average (two

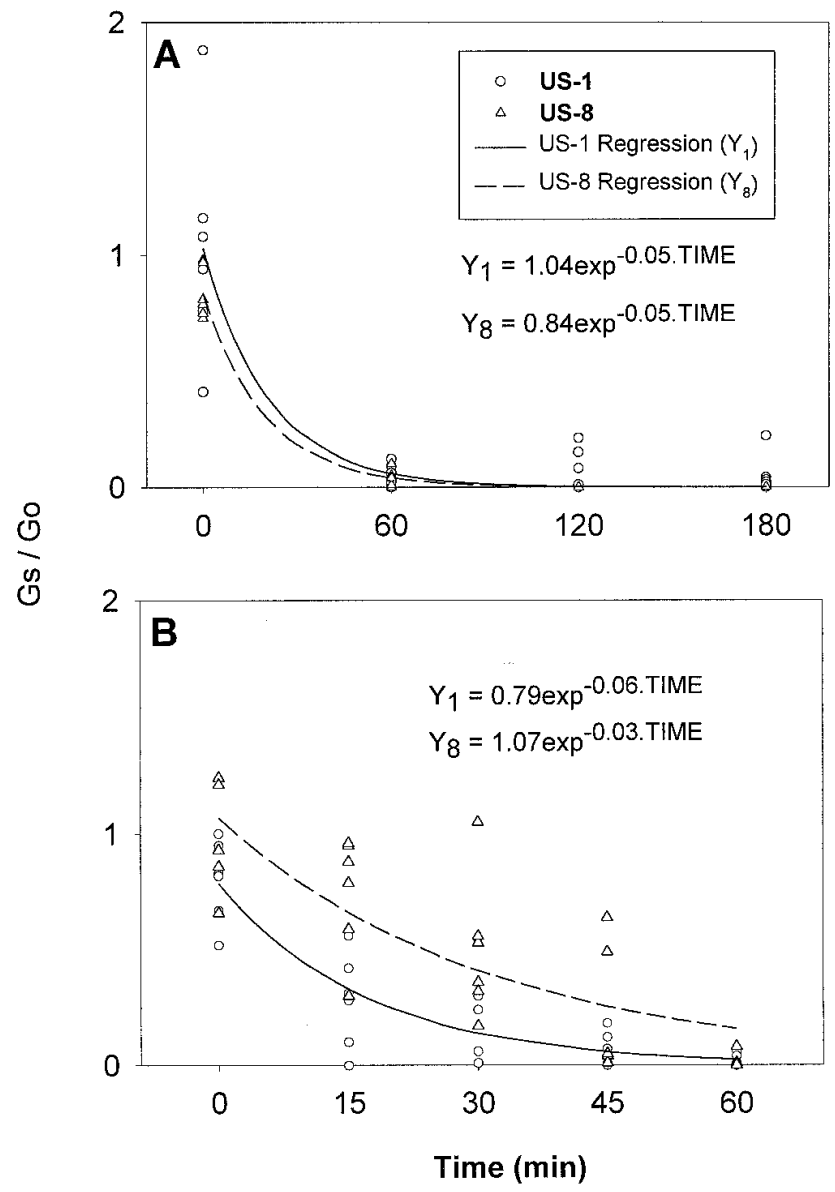

Fig. 3. Standardized germination rates $\left(G_{\mathrm{S}} / G_{0}\right)$ of sporangia of isolates belonging to two clonal lineages of Phytophthora infestans, US-1 and US-8, as a function of duration of exposure during $\mathbf{A}$, sunny days for $3 \mathrm{~h}$ from 1100 to $1400 \mathrm{~h}$, and B, sunny days for $1 \mathrm{~h}$ from 1100 to $1200 \mathrm{~h}$. Standardized germination rate was calculated by dividing the absolute germination percentages of sporangia exposed to solar irradiance $\left(G_{\mathrm{S}}\right)$ by the average of the absolute germination percentage of nonexposed $(\mathrm{N})$ sporangia at the beginning of the exposure (time $0 ; G_{0}$ ). 
experiments) dose for the intervals from 0800 to 1100,1100 to 1400 , and 1400 to $1700 \mathrm{~h}$, were 3.8, 6.9, and $5.0 \mathrm{MJ} / \mathrm{m}^{2}$, respectively. Average temperature and $\mathrm{RH}$ (two experiments) for the same intervals were $22.2,32.2$, and $35.6^{\circ} \mathrm{C}$ and $84.9,60.7$, and $56.3 \%$, respectively.

Experiment 2. Under sunny conditions, sporangium viability of both isolates decreased rapidly and exponentially with time, whether they were directly exposed to solar radiation (S) or shielded from direct sunlight (C). Sporangia that were not exposed to SI (N) lost viability much more slowly (Fig. 2A and B). Exposure for $1 \mathrm{~h}$ reduced sporangium viability in both the exposed (S) and covered (C) treatments (Fig. 2A and B). The average absolute germination percentage (two experiments) of sporangia in treatment $\mathrm{N}$ at time 0 was 27.30 and $52.90 \%$ for US- 1 and US- 8 isolates, respectively. The effective times to inactivate $95 \%$ of the sporangia ( $\mathrm{ET}_{95}$ ) of US-1 and US-8 isolates were not significantly different and were estimated to be 62.4 and $55.5 \mathrm{~min}$, respectively (Fig. 3A). The effective dose to inactivate $95 \%$ of the sporangia $\left(\mathrm{ED}_{95}\right)$ was calculated to be 2.36 and $1.66 \mathrm{MJ} / \mathrm{m}^{2}$ for the US-1 and US-8 isolates, respectively (Fig. $4 \mathrm{~A})$. These $\mathrm{ED}_{95}$ values were not significantly different $(\alpha=0.05)$. The average temperature of the different trials ranged from 25.6 to $30.2^{\circ} \mathrm{C}$, and the average cumulative SI dose for $180 \mathrm{~min}$ was 8.9 and $6.5 \mathrm{MJ} / \mathrm{m}^{2}$ for experiments with the US-1 and US- 8 isolates, respectively (Fig. 5A).

Cloudy conditions (overcast, SI $<300 \mathrm{~W} / \mathrm{m}^{2}$ ) were much less detrimental to germination of sporangia than were sunny conditions (Fig. 2C and D). Sporangia remained viable for up to $3 \mathrm{~h}$ on days
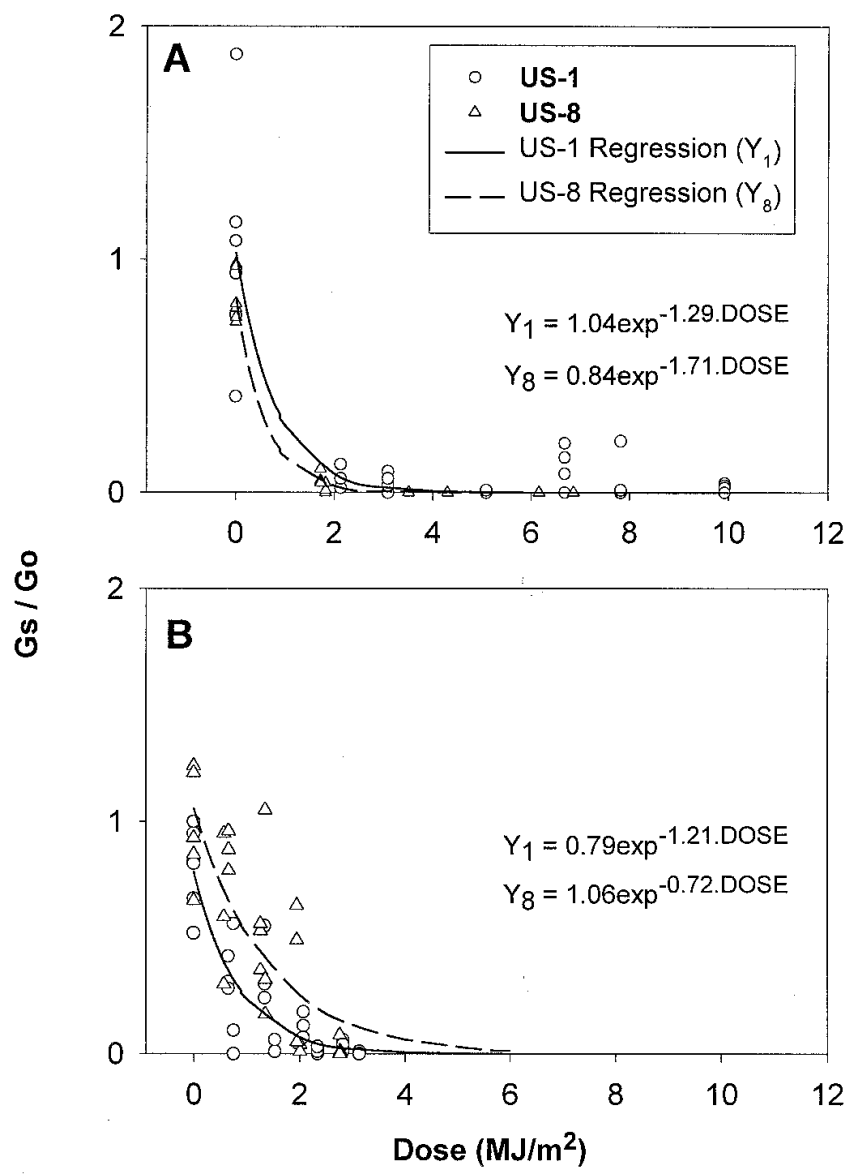

Fig. 4. Standardized germination rates $\left(G_{\mathrm{S}} / G_{0}\right)$ of sporangia of isolates belonging to two clonal lineages of Phytophthora infestans, US-1 and US-8, as a function of cumulative solar irradiance (megajoules per square meter) dose during exposures on A, sunny days for $3 \mathrm{~h}$ from 1100 to $1400 \mathrm{~h}$, and $\mathbf{B}$, sunny days for $1 \mathrm{~h}$ from 1100 to $1200 \mathrm{~h}$. Standardized germination was calculated by dividing the absolute germination percentages of sporangia exposed to solar irradiance $\left(G_{\mathrm{S}}\right)$ by the average of the absolute germination percentage of nonexposed sporangia at the beginning of the exposure (time $0 ; G_{0}$ ). with overcast skies (Fig. 6A). When the cumulative dose of total SI was less than $2.8 \mathrm{MJ} / \mathrm{m}^{2}$, viability was reduced only slightly (Fig. 6B). The linear correlation coefficients between viability, measured by $\ln \left(G_{\mathrm{S}} / \mathrm{G}_{0}\right)$, and dose, time, temperature, or RH were significant $(P<0.001, P=0.031, P=0.024$, and $P=0.006$, respectively) (Table 3 ). The average absolute germination percentage (two experiments) of sporangia in treatment $\mathrm{N}$ at time 0 was 77.80 and $79.40 \%$ for the US- 1 and US- 8 isolates, respectively. There was no significant difference $(\alpha=0.05)$ between the slopes of the nonlinear regression functions of viability as a function of dose for the US-1 and US-8 isolates for experiments conducted on cloudy days.

Temperature and $\mathrm{RH}$ during experiments conducted on sunny and overcast days were different. Average temperature and RH during experiments conducted on sunny days were $27.7^{\circ} \mathrm{C}( \pm 2.4)$ and $65.2 \%$ ( \pm 8.4$)$, respectively, and on overcast days were $25.0^{\circ} \mathrm{C}( \pm 3.3)$ and $85.5 \%( \pm 9.7)$, respectively. The average cumulative SI dose for samples exposed for $180 \mathrm{~min}$ on cloudy days was 5.6 and $3.3 \mathrm{MJ} / \mathrm{m}^{2}$ for the US-1 and US-8 clonal lineages, respectively (Fig. 5B).

Experiment 3. Viability of sporangia declined within $15 \mathrm{~min}$ of exposure on sunny days. In contrast, the viability of nonexposed sporangia declined much more slowly, and survival of sporangia in the covered treatment (C) generally was intermediate (Fig. 2E and $\mathrm{F}$ ). The average absolute germination percentage (two experiments) of sporangia in the nonexposed treatment $(\mathrm{N})$ at time 0 was

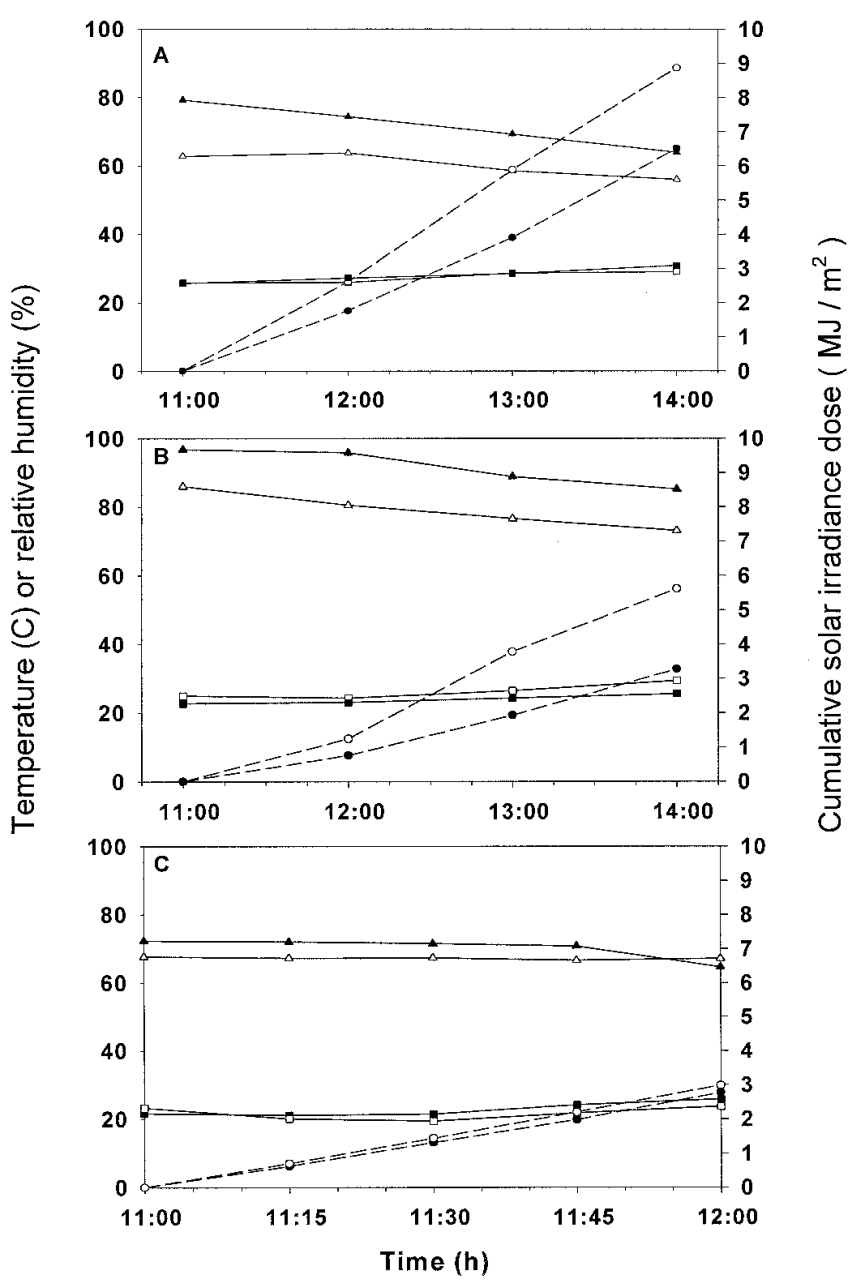

Fig. 5. Average temperature (squares), relative humidity (triangles), and cumulative solar irradiance dose (dashed lines with circles) measured in experiments conducted during A, sunny days for $3 \mathrm{~h}$ from 1100 to $1400 \mathrm{~h} ; \mathbf{B}$, cloudy days for $3 \mathrm{~h}$ from 1100 to $1400 \mathrm{~h}$; and $\mathbf{C}$, a sunny day for $1 \mathrm{~h}$ from 1100 to $1200 \mathrm{~h}$. Hollow symbols indicate experiments with the Phytophthora infestans US-1 clonal lineage isolate; solid symbols indicate experiments with the US-8 clonal lineage isolate. 
74.8 and $64.3 \%$ for the isolates of US- 1 and US-8 lineages, respectively. The $\mathrm{ET}_{95}$ for the US-1 isolate was calculated as $42.2 \mathrm{~min}$ and the $\mathrm{ET}_{95}$ for the US-8 isolate was calculated as $99.8 \mathrm{~min}$ (Fig. 3B). $\mathrm{ED}_{95}$ 's were calculated as 2.00 and $4.42 \mathrm{MJ} / \mathrm{m}^{2}$ for the US-1 and US-8 isolates, respectively (Fig. 4B). The values of $\mathrm{ET}_{95}$ and
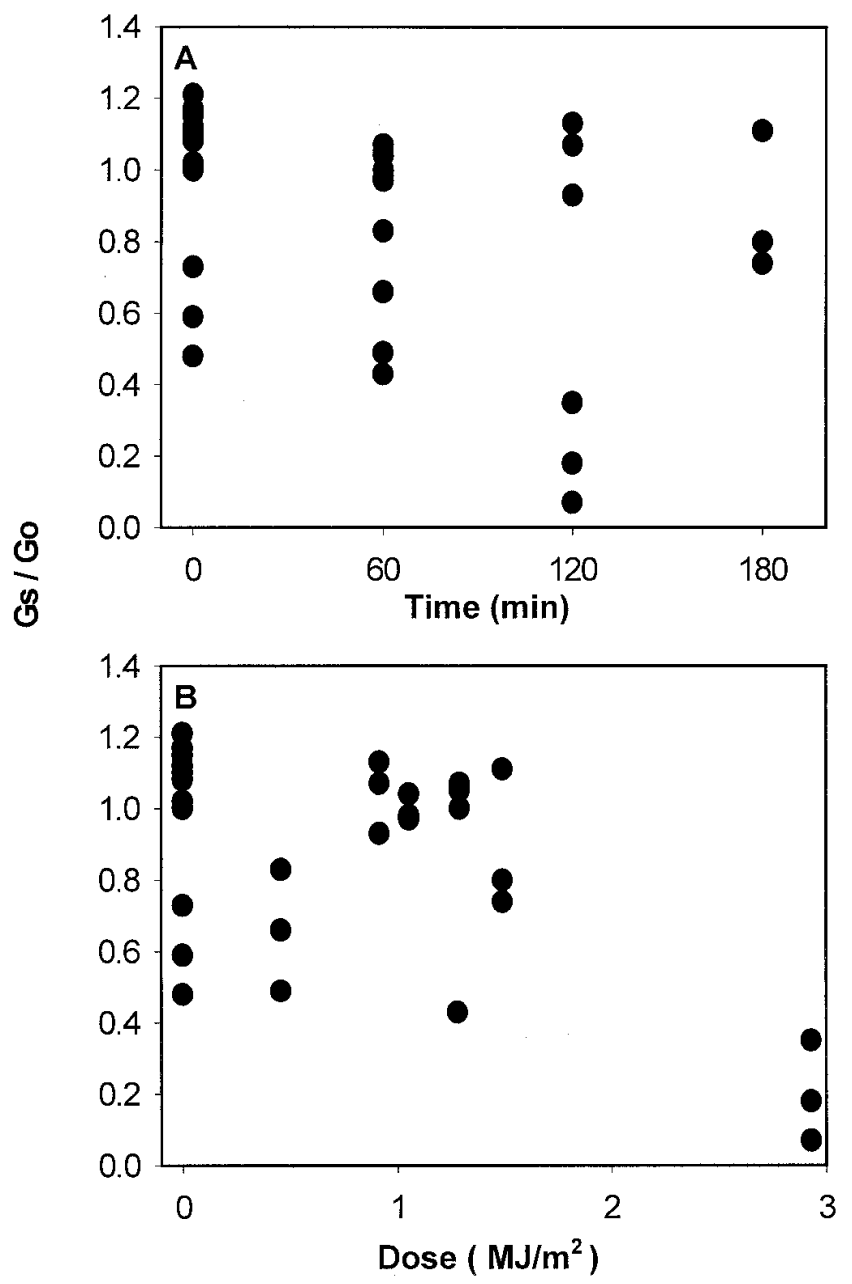

Fig. 6. Standardized germination rates $\left(G_{S} / G_{0}\right)$ of sporangia of isolates belonging to two clonal lineages of Phytophthora infestans, US-1 and US-8, as a function of length of exposure (minutes) during cloudy days when maximum cumulative solar radiation dose was $<3.0 \mathrm{MJ} / \mathrm{m}^{2}$. Standardized germination was calculated by dividing the absolute germination percentages of sporangia exposed to solar irradiance $\left(G_{\mathrm{S}}\right)$ by the average of the absolute germination percentage of nonexposed sporangia at the beginning of the exposure (time $\left.0 ; G_{0}\right)$. Viability $\left(G_{S} / G_{0}\right)$ is presented as a function of $\mathbf{A}$, time or $\mathbf{B}$, cumulative exposure.
$\mathrm{ED}_{95}$ for the US-1 isolate were significantly different from those for the US-8 isolate.

The average temperatures of different trials ranged from 19.4 to $25.7^{\circ} \mathrm{C}$, and average cumulative SI doses for samples exposed for $60 \mathrm{~min}$ were 3.0 and $2.8 \mathrm{MJ} / \mathrm{m}^{2}$ for experiments with isolates of the US-1 and US-8 clonal lineages, respectively (Fig. 5C).

As observed in previous experiments, the correlation coefficients between viability and exposure time or dose were highly significant $(P<0.0001)$. There was no significant correlation between viability and temperature $(P=1.000)$ or RH $(P=0.191$; Table 3$)$.

\section{DISCUSSION}

SI drastically reduced the viability of $P$. infestans sporangia on sunny days but not on cloudy days. Regardless of the time of the day $(0800$ to $1700 \mathrm{~h})$, viability during a sunny day was reduced to almost zero if the total SI dose was higher than $2.6 \mathrm{MJ} / \mathrm{m}^{2}( \pm 1.2)$ a dose easily attained in $3 \mathrm{~h}$, or even in $1 \mathrm{~h}$ on some days. In contrast, survival of $P$. infestans sporangia during overcast days was longer and was measurable after $2 \mathrm{~h}$ and even $3 \mathrm{~h}$ of exposure (Fig. 2D).

The same total SI dose on a cloudy day $\left(2.6 \mathrm{MJ} / \mathrm{m}^{2}\right)$ had a different effect on sporangium viability than it did on a sunny day. The mechanism for the differential effect is not yet certain. We hypothesize that the amount of active irradiance might be differentially less on cloudy days than on sunny days.

Different exposure conditions for the US-1 isolate relative to those for the US-8 isolate might have created some misleading impressions about differences in sensitivity to exposure for the two isolates. The drop in standardized percent germination on partly cloudy days usually was associated with a reducing fraction of sky coverage and increase in SI (Fig. 5B). For instance, the decline in sporangia viability at $120 \mathrm{~min}$ for the US-1 clonal lineage isolate during partly cloudy days (Fig. 2C) coincided with the increase in cumulative SI dose at $1300 \mathrm{~h}$ (Fig. 5B). This fact corroborates the findings that on sunny days sporangia lost viability when exposed for $\approx 1 \mathrm{~h}$. Although we tried to conduct related experiments under

TABLE 4. Range of weather variables measured during experiments

\begin{tabular}{|c|c|}
\hline Variable & Range \\
\hline Cumulative solar irradiance dose & $0-9.9 \mathrm{MJ} / \mathrm{m}^{2}$ \\
\hline Temperature of membrane directly exposed to the sun & $15.7-32.6^{\circ} \mathrm{C}$ \\
\hline Temperature of membrane shaded & $15.4-31.8^{\circ} \mathrm{C}$ \\
\hline Temperature inside laboratory & $23.0-30.0^{\circ} \mathrm{C}$ \\
\hline Relative humidity & $40.3-98.4 \%$ \\
\hline Average wind speed ${ }^{\mathrm{a}}$ & $1.1-5.2 \mathrm{~m} / \mathrm{s}$ \\
\hline Average temperature range ${ }^{a}$ & $16.6-28.9^{\circ} \mathrm{C}$ \\
\hline Relative humidity ${ }^{\mathrm{a}}$ & $50.0-98 \%$ \\
\hline
\end{tabular}

a Measured at a standard weather station during the time course of the experiments.

TABLE 3. Matrix of Pearson correlation coefficients $(P)$ of standardized germination percents $\left(\ln \left(G_{\mathrm{S}} / G_{0}\right)\right)$ with weather variables ${ }^{\mathrm{a}}$

\begin{tabular}{|c|c|c|c|c|c|}
\hline & $\ln \left(G_{S} / G_{0}\right)$ & Dose & Time & Temp. ${ }^{b}$ & $\mathrm{RH}^{\mathrm{c}}$ \\
\hline $\ln \left(G_{\mathrm{S}} / G_{0}\right)$ & $\begin{array}{l}1.00^{\mathrm{d}} \\
1.00\end{array}$ & & & & \\
\hline Dose $\left(\mathrm{MJ} / \mathrm{m}^{2}\right)$ & $\begin{array}{l}-0.83(0.0001)^{\mathrm{e}} \\
-0.93(0.0001)\end{array}$ & $\begin{array}{l}1.00 \\
1.00\end{array}$ & & & \\
\hline Time $(\min )$ & $\begin{array}{l}-0.79(0.0001) \\
-0.69(0.0310)\end{array}$ & $\begin{array}{l}0.99(0.0001) \\
0.85(0.0001)\end{array}$ & $\begin{array}{l}1.00 \\
1.00\end{array}$ & & \\
\hline Temp. ${ }^{\mathrm{b}}\left({ }^{\circ} \mathrm{C}\right)$ & $\begin{array}{l}-0.22(1.0000) \\
-0.70(0.0240)\end{array}$ & $\begin{array}{l}0.36(1.0000) \\
0.72(0.0170)\end{array}$ & $\begin{array}{l}0.41(0.7555) \\
0.43(0.9720)\end{array}$ & $\begin{array}{l}1.00 \\
1.00\end{array}$ & \\
\hline $\mathrm{RH}^{\mathrm{c}}(\%)$ & $\begin{array}{l}0.52(0.1910) \\
0.76(0.0060)\end{array}$ & $\begin{array}{l}-0.36(1.0000) \\
-0.77(0.0050)\end{array}$ & $\begin{array}{l}-0.36(1.0000) \\
-0.50(0.4820)\end{array}$ & $\begin{array}{l}-0.35(1.0000) \\
-0.61(0.1170)\end{array}$ & $\begin{array}{l}1.00 \\
1.00\end{array}$ \\
\hline
\end{tabular}

a Coefficient values in normal type refer to 1-h experiments. Coefficient values in italic type refer to 3-h, cloudy day experiments.

b Temperature of membrane filter exposed to the sun.

c Relative humidity.

d Correlation coefficient $(P)$.

e Bonferroni-adjusted significance level for overall $\alpha=0.05$. 
similar environmental conditions, weather conditions often varied from one trial to another. Sometimes a rain event terminated an experiment for exposure to cloudy conditions. We believe that changes in exposure conditions rather than differences among isolates is responsible for the apparent greater sensitivity of US-1 sporangia to SI compared with US-8 sporangia.

Contrary to our expectation, sporangia that were covered ( $\mathrm{C}$ treatment) lost viability as rapidly as sporangia directly exposed to sunlight (S treatment). It seems likely that the roof built to create shading conditions did not reduce the amount of UV-B that reached the sporangia. Short wavelength radiation is more readily scattered than long wavelength radiation $(4,25)$, and we believe that scattered UV radiation reached covered sporangia.

Even though temperature and $\mathrm{RH}$ are important factors affecting sporangium viability (23), they were not important variables in our experiments. All sporangia for a given experiment were exposed to similar temperatures, whether sporangia were kept in the sun, under shade, or inside the laboratory. The temperature range inside the laboratory was 23.0 to $30.0^{\circ} \mathrm{C}$ (Table 4), which was similar to the range observed for sporangia subjected to outdoor treatments (Fig. 5). There was no significant correlation between $\ln \left(G_{\mathrm{S}} / G_{0}\right)$ and temperature $(r=-0.22, P=1.000)$ or between $\ln \left(G_{\mathrm{S}} / G_{0}\right)$ and $\mathrm{RH}$ $(r=0.52, P=0.191)$ (Table 3$)$ when sporangia were exposed on sunny days for $1 \mathrm{~h}$. In contrast, a highly significant correlation with irradiance dose $(r=-0.83, P<0.001)$ (Table 3$)$ supports the hypothesis that SI was the major factor responsible for reductions in sporangia viability.

The results of our experiments permit construction of a conceptual model of sporangium dispersal. Because sporangia are rapidly inactivated by SI on a sunny day, successful transport would be limited to short periods (i.e., short distances) on sunny days. Sporangia landing on shaded areas of plants probably have a better chance of surviving the rest of the day until conditions favorable for germination occur. In addition to lower SI levels, shaded areas tend to experience lower temperatures and higher $\mathrm{RH}$, which also favor sporangium survival $(23,27)$. In contrast to sunny conditions, cloudy conditions permit longer survival of sporangia, and the importance of cloudy conditions might be reflected in one of the earliest forecast models, which required cloudy conditions for late blight development (31). However, sporulation may be limited during cloudy conditions because dew formation is less during cloudy compared with clear conditions. Removal of sporangia from lesions also may be limited during cloudy conditions, because the process probably requires rapid declines in $\mathrm{RH}$, which are typical of sunny mornings. Thus, although a conceptual model is readily constructed, a quantitative model is likely to be complex and should include the competing components of sporulation and dispersal (generally favored by clear conditions) and survival (favored by cloudy conditions).

\section{LITERATURE CITED}

1. Aylor, D. E. 1978. Dispersal in time and space: Aerial pathogens. Pages 159-180 in: Plant Disease: An Advanced Treatise. J. G. Horsfall and E. B. Cowling, eds. Academic Press, New York.

2. Aylor, D. E., and Sanogo, S. 1997. Germinability of Venturia inaequalis conidia exposed to sunlight. Phytopathology 87:628-633.

3. Aylor, D. E., Taylor, G. S., and Raynor, G. S. 1982. Long-range transport of tobacco blue mold spores. Agric. Meteorol. 27:217-232.

4. Bais, A. F., Zerefos, C. S., Meleti, C., Ziomas, I. C., and Tourpali, K. 1993. Spectral measurements of solar UVB radiation and its relations to total ozone, $\mathrm{SO}_{2}$, and clouds. J. Geophys. Res. 98:5199-5204.

5. Bashi, E., and Aylor, D. E. 1983. Survival of detached sporangia of Peronospora destructor and Peronospora tabacina. Phytopathology 73:11351139.
6. Bashi, E., Ben-Joseph, Y., and Rotem, J. 1982. Inoculum potential of Phytophthora infestans and the development of potato late blight. Phytopathology 72:1043-1047.

7. Bowden, J., Gregory, P. H., and Johnson, C. G. 1971. Possible wind transport of coffee leaf rust across the Atlantic Ocean. Nature (Lond.) 229: 500-501.

8. Cox, A. E., and Large, E. C. 1960. Potato blight epidemics throughout the world. ARS USDA Handbook No. 174. U.S. Government Printing Office, Washington DC

9. Davis, J. M. 1987. Modeling the long-range transport of plant pathogens in the atmosphere. Annu. Rev. Phytopathol. 25:169-188.

10. De Weille, G. A. 1964. Forecasting crop infection by the potato blight fungus. Med. Verhand. 82:1-144.

11. Diffey, B. L. 1991. Solar ultraviolet radiation effects on biological systems. Phys. Med. Biol. 36:299-328.

12. Glendinning, D., MacDonald, J. A., and Grainger, J. 1963. Factors affecting the germination of sporangia in Phytophthora infestans. Trans. Br. Mycol. Soc. 46:595-603.

13. Goodwin, S. B., Cohen, B. A., and Fry, W. E. 1994. Panglobal distribution of a single clonal lineage of the Irish potato famine fungus. Proc. Natl. Acad. Sci. USA 91:11591-11595.

14. Gregory, P. H. 1945. The dispersion of air-borne spores. Trans. Br. Mycol. Soc. 28:26-72.

15. Harrison, J. G. 1992. Effects of the aerial environment on late blight of potato foliage-A review. Plant Pathol. 41:384-416.

16. Hildebrand, P. D., and Sutton, J. C. 1984. Effects of weather variables on spore survival and infection of onion leaves by Peronospora destructor. Can. J. Plant Pathol. 6:119-126.

17. Hirst, J. M. 1953. Changes in atmospheric spore content: Diurnal periodicity and the effects of weather. Trans. Br. Mycol. Soc. 36:375-393.

18. Hirst, J. M. 1959. Spore liberation and dispersal. Pages 529-538 in: Plant Pathology: Problems and Progress 1908-1958. C. S. Holton, G. W. Fischer, R. W. Fulton, H. Hart, and S. E. A. McCallan, eds. The American Phytopathological Society, St. Paul, MN.

19. Kawamura, C., Tsujimoto, T., and Tsuge, T. 1999. Targeted disruption of a melanin biosynthesis gene affects conidial development and UV tolerance in the Japanese pear pathotype of Alternaria alternata. Mol. PlantMicrobe Interact. 12:59-63.

20. Kuehl, R. O. 1994. Statistical Principles of Research Design and Analysis. Duxbury Press, Belmont, CA.

21. Maddison, A. C., and Manners, J. G. 1972. Sunlight and viability of cereal rust uredospores. Trans. Br. Mycol. Soc. 59:429-443.

22. McCartney, H. A., and Fitt, B. D. L. 1987. Spore dispersal gradients and plant disease development. Pages 109-118 in: Populations of Plant Pathogens: Their Dynamics and Genetics. M. S. Wolfe and C. E. Caten, eds. Blackwell Scientific Publications, Oxford.

23. Minogue, K. P., and Fry, W. E. 1981. Effect of temperature, relative humidity, and rehydration rate on germination of dried sporangia of Phytophthora infestans. Phytopathology 71:1181-1184.

24. Mizubuti, E. S. G., and Fry, W. E. 1998. Temperature effects on developmental stages of isolates from three clonal lineages of Phytophthora infestans. Phytopathology 88:837-843.

25. Oke, T. R. 1987. Boundary layer climates. Routledge, Chapman, \& Hall, London.

26. Rotem, J., and Aust, H. J. 1991. The effect of ultraviolet and solar radiation and temperature on survival of fungal propagules. J. Phytopathol. 133:76-84.

27. Rotem, J., and Cohen, Y. 1974. Epidemiological patterns of Phytophthora infestans under semi-arid conditions. Phytopathology 64:711-714.

28. Rotem, J., Palti, J., and Lomas, J. 1970. Effects of sprinkler irrigation at various times of the day on development of potato late blight. Phytopathology 60:839-843.

29. Rotem, J., Wooding, B., and Aylor, D. E. 1985. The role of solar radiation, especially ultraviolet, in the mortality of fungal spores. Phytopathology 75:510-514.

30. Snedecor, G. W., and Cochran, W. G. 1989. Statistical Methods. Iowa State University Press, Ames.

31. Van Everdingen, E. 1926. Het verband tusschen de weersgesteldheid en de aardappelziekte (Phytophthora infestans). Tijdschr. Plantenziekten 32:129140.

32. Visser, T., Shanmuganathan, N., and Sabanayagam, J. V. 1961. The influence of sunshine and rain on tea blister blight, Exobasidium vexans Massee, in Ceylon. Ann. Appl. Biol. 49:306-315. 